\title{
II CONGRESS ON MENTAL HEALTH. MEETING THE NEEDS OF THE XXI CENTURY. MOSCOW, RUSSIAN FEDERATION, 5-7 OCTOBER 2018
}

The underlying theme of this congress organized by the Union for Mental Health of Russia in Moscow was education and its relation to mental health. A related concern was the impact of mental health on education.

It is worth reminding that any social interest must be considered in the context of its ethical implications. This is the reason why the emphasis of the meeting should be highlighted. The main challenges ahead for the health professions are not only technical. They are also moral imperatives confronting the ideals and expectations of societies and the need to deliberate on ends and means to achieve social harmony.

The congress was inaugurated by an impressive number of officials from different areas, including ministries of education, sport, and health. It is an important accomplishment of the organizers to have brought together stakeholders from different groups and to have emphasized the critical role of professional and lay education in the field of mental health.

There can be no doubt that under the term education different topics and expectations are included. In essence, the idea is to promote understanding and sensitivity to the issues implied in the vague but crucial idea of mental health. It is vident that there is no health without mental health. The adjective mental adds the dimension of personal and societal involvement.

For an impartial observer, linking health with a state of almost perfect wellbeing is misleading. It conveys the impression that such plenitude can be achieved by the means provided by modern societies, either the State or the Market. Reality indicates that all healthcare systems enter periodically into periods of crisis and that the future will probably depend on the empowerment of people concerned. Demands grow but supplies are short. Every day new expectations arise. People expect from science and economy that their personal needs will be satisfied. Frustration ensues when reality does not meet the expectations.

Perhaps a solution to this dilemma could be to return to the idea of health as a neutral state. Not complete "sanitas", but not "infirmitas". Something in between. A region of comfort where difficulties are recognized, problems acknowledged, expectations are realistic and personal involvement crucial. Every person is responsible for his/her own state of health and should demand what is technically and economically feasible in the community. There is a right to healthcare but it is difficult to demand a right to health, which always is a personal construction.

Psychiatric expertise would probably not be enough to satisfy all demands. It is not only a matter of technical expertise. From the papers presented in this meeting, it can be concluded that the many aspects implied in the relationship between education and health are vast, complex, and in need of interdisciplinary collaboration. Education is not simply transference of knowledge and skills. It is also a permanent change in attitudes, tolerance, and acceptance of diverse wolrdwiews and abilities.

The topics covered in the Moscow congress, its successful organization and the great number of participants permit to conclude that it was an unforgettable event that should be repeated. A collection of scientific papers (mostly in Russian) was published (ISBN 978-5-907085-05-3)

Fernando Lolas Stepke 